Brit. F. vener. Dis. (1969), 45, 1.

\title{
EVALUATION OF DARKFIELD AND IMMUNOFLUORESCENT TECHNIQUES FOR DEMONSTRATING Treponema pallidum IN FLUIDS WITH SMALL NUMBERS OF ORGANISMS*†
}

\author{
BY \\ FRANCIS W. CHANDLER, JR., AND GEORGE R. CANNEFAX \\ Venereal Disease Research Laboratory, Venereal Disease Program, \\ National Communicable Disease Center, \\ Health Services and Mental Health Administration, \\ Public Health Service, \\ U.S. Department of Health, Education, and Welfare, \\ Atlanta, Georgia 30333
}

Spiral organisms that are morphologically indistinguishable from Treponema pallidum and react with fluorescein-tagged, anti- $T$. pallidum rabbit globulin have recently been detected in the aqueous humour (AH) and cerebrospinal fluid (CSF) of syphilitics (Girard, Goldman, Baumstark, and Stickle, 1967; Goldman and Girard, 1968; Smith and Israel, 1967a, b; Wells and Smith, 1967; Wilkinson and Jones, 1967). The organisms, which may or may not be motile, are few in number and difficult to demonstrate despite prolonged microscopical examination. This paper evaluates a microhaematocrit-tube centrifugation method for the concentration of small numbers of $T$. pallidum and the relative efficiencies of direct immunofluorescent and darkfield examinations based on the recovery of known numbers of organisms.

\section{Material and Methods}

Equipment The New International Microcapillary Centrifuge, Model MB, equipped with No. 275 interchangeable 24-place head, was used at 13,160 relative centrifugal force (RCF). A Sorvall, Type SS-1, AngleHead Centrifuge was used to produce a force of 1,375 RCF and 4,746 RCF. Centrifuge speeds were checked frequently by using a Type 1531-A Strobotac (electronic stroboscope $\ddagger$ with an accuracy of \pm 1 per cent.

Standard $1.5 \times 75-\mathrm{mm}$. red-marked microhaematocrit tubes were sealed with Critocaps.§ The plastic caps provide not only adequate closure but also immediate accessibility to the sediment after centrifugation.

*Received for publication August 26, 1968.

† Trade names are used for identification only and do not represent an endorsement by the Public Health Service or the U.S. Department of Health, Education, and Welfare.

$\ddagger$ General Radio Company, West Concord, Massachusetts.

\$Aloe Scientific, Division of Brunswick, St. Louis, Missouri.

\section{Preparation of $\boldsymbol{T}$. pallidum Suspension}

Source. T. pallidum organisms were extracted from rabbit testicular syphilomata as recommended for the Treponema pallidum Immobilization (TPI) test (U.S. Public Health Service, 1964), by using $0.15 \mathrm{M} \mathrm{NaCl}$ instead of the usual TPI test medium. The extract was centrifuged for $5 \mathrm{~min}$. at $650 \mathrm{RCF}$ to free the suspension of gross tissue debris. The supernatant fluid provided the control treponeme suspension.

Enumeration. The number of organisms per $\mathrm{ml}$. was determined by the method of Morgan and Vryonis (1938) as follows: $10 \mu \mathrm{l}$. were placed on a slide and covered with a $22 \times 22-\mathrm{mm}$. coverslip so that the fluid was evenly distributed and devoid of air bubbles. The calculated fluid depth was $0.0207 \mathrm{~mm}$. The diameter of the microscopic field, which varies with each microscope, was determined by use of a slide micrometer to be $0.41 \mathrm{~mm}$. From these data the volume of fluid per field was calculated to be $2.73 \times 10^{-6} \mathrm{ml}$, and one organism per high dry field (hdf) (440X) represented a suspension containing $3.66 \times 10^{5}$ organisms per $\mathrm{ml}$. For use in centrifugation and recovery studies, and to establish a reproducible base line, the control suspension was diluted with $0.15 \mathrm{M} \mathrm{NaCl}$ to provide approximately one organism per hdf and 21,960 organisms per microhaematocrit tube.

\section{Experimental Procedures}

Twelve variations of RCF, centrifuging time, and tube levels of sampling were investigated. Forces of $1,375,4,746$, and 13,160 RCF were employed with centrifuging times of $3,10,30,60$, and $120 \mathrm{~min}$. Each combination of variables was evaluated for recovery of organisms from $60 \mu \mathrm{l}$. of control suspension (21,960 treponemes) in sixteen microhaematocrit tubes - eight with the darkfield method and eight with the direct 
fluorescent antibody (FA) method. The control suspension was checked for uniformity of dispersion and number of organisms per ml. before each evaluation.

The recovery of organisms by the direct FA method was evaluated by using samples of approximately $10 \mu \mathrm{l}$. spread within a circle $1 \mathrm{~cm}$. in diameter, with one sample per slide. After air drying, the slides were immersed in acetone and stained by the direct FA technique (Venereal Disease Research Laboratory, 1967) by using fluorescein-tagged anti- $T$. pallidum rabbit globulin produced in this laboratory (Lot No. 712227R2) that had common antibody removed by adsorption with Reiter treponemes (Deacon and Hunter, 1962; Meyer and Hunter, 1967). Positive and negative control slides were included with each staining of experimental slides.

The number of organisms recovered with the FA method could not be calculated by the factor used for the darkfield method. The 10- $\mu 1$. samples were confined in a $1-\mathrm{cm}$. circle, compared with the $22 \times 22-\mathrm{mm}$. coverslip of the darkfield method, and, since the FA sample was dried, the fluid depth and the area of sample dispersion were not common to the two methods. The number of recovered organisms detected by the FA method was calculated by multiplying the average number of organisms per field by the conversion factor 595. The factor was determined by dividing the area of the $1-\mathrm{cm}$. circle $(78.54 \mathrm{sq} . \mathrm{mm}$.) by the area of one microscopic field ( 0.132 sq. $\mathrm{mm}$.).

Recovered organisms detected by the darkfield method, with 10- $\mu$ l. samples, were counted in the same manner as the organisms of the control treponeme suspension. The number of recovered organisms in $10-\mu 1$. samples detected with the darkfield method was calculated by multiplying the average number of organisms per field by the conversion factor 3,666 .

\section{Results}

Tables I, II, and III show values derived from counts of 800 fields; these counts resulted from observing 100 random fields per slide prepared from $10-\mu l$. sediments of eight centrifuged $60-\mu l$. samples of the standard suspension. The study involved counting organisms in more than 21,000 random fields.

Table I shows that the recovery of $T$. pallidum progressively increased with increases in RCF with a constant centrifuging time of $30 \mathrm{~min}$. Analysis of variance of samples centrifuged for $30 \mathrm{~min}$. at $1,375,4,746$, and 13,160 RCF showed differences significant beyond the 0.001 level for the FA and darkfield procedures.

At $13,160 \mathrm{RCF}$, no fragmentation or deviation from the typical morphology was evident, and, when stained by the direct FA technique, the organisms demonstrated strong fluorescence $(3+$ or $4+$ ) with a uniform affinity for the conjugate.

It is shown in Table II that the recovery of $T$. pallidum increased with increments of centrifugation time at $13,160 \mathrm{RCF}$. The data demonstrate that the number of treponemes recovered at 13,160 RCF increased very little with time after $30 \mathrm{~min}$. of centrifugation. Analysis of variance of samples centrifuged at $13,160 \mathrm{RCF}$ for $3,10,30,60$, and $120 \mathrm{~min}$. showed variance significant beyond the 0.001 level for the FA and darkfield procedures; furthermore, comparison of samples centrifuged for 3,10 , and $30 \mathrm{~min}$. showed variance significant beyond the 0.001 level for both procedures, but comparison of samples centrifuged for 30,60 , and $120 \mathrm{~min}$. showed no significant variance for either procedure.

Table III shows that there was an appreciable increase in treponemal recovery when the centrifuged suspension was dispersed with the inner surface of the Critocap. It is apparent that many organisms adhere to the Critocap surface, and more of these are recovered if firm pressure is applied to the Critocap and a circular motion is used to disperse the adhered and packed sediment. Analysis of variance of samples drawn from the four tube

TABLE I

DARKFIELD AND DIRECT IMMUNOFLUORESCENT EXAMINATIONS OF 60 MI. OF TREPONEMA PALLIDUM SUSPENSIONS HAVING ONE ORGANISM PER DARKFIELD (440 X) CENTRIFUGED AT VARIOUS RELATIVE CENTRIFUGAL FORCES FOR $30 \mathrm{MIN}$.

\begin{tabular}{|c|c|c|c|c|c|c|c|c|}
\hline \multirow{3}{*}{$\begin{array}{c}\text { Relative } \\
\text { Centrifugal } \\
\text { Force }\end{array}$} & \multicolumn{4}{|c|}{ Organisms per High Dry Field } & \multicolumn{4}{|c|}{ Organisms Recovered $\dagger$} \\
\hline & \multicolumn{2}{|c|}{ Average* } & \multicolumn{2}{|c|}{ Range } & \multicolumn{2}{|c|}{ Number } & \multicolumn{2}{|c|}{ Per cent. } \\
\hline & DF & FA & DF & FA & DF & FA & DF & FA \\
\hline $\begin{array}{r}1,375 \\
4,746 \\
13,160\end{array}$ & $\begin{array}{l}1.80 \\
2.04 \\
3.06\end{array}$ & $\begin{array}{l}3.30 \\
3.72 \\
4.92\end{array}$ & $\begin{array}{l}1.44-2.09 \\
1.71-2.43 \\
2.69-3.51\end{array}$ & $\begin{array}{l}2 \cdot 40-4 \cdot 02 \\
2 \cdot 22-4 \cdot 44 \\
4 \cdot 02-5 \cdot 52\end{array}$ & $\begin{array}{r}6,599 \\
7,479 \\
11,218\end{array}$ & $\begin{array}{l}1,964 \\
2,213 \\
2,927\end{array}$ & $\begin{array}{l}30 \cdot 0 \\
34 \cdot 1 \\
51 \cdot 1\end{array}$ & $\begin{array}{r}8 \cdot 9 \\
10 \cdot 1 \\
13 \cdot 3\end{array}$ \\
\hline
\end{tabular}

*Average values of 800 random fields derived from 100 fields of 10 - $\mu$ l. samples from the bottom portion of eight centrifuged microhaematocrit tubes.

†Total recoverable organisms in $60 \mu \mathrm{l}$. calculated by the darkfield method to be 21,960 . 
TABLE II

DARKFIELD AND DIRECT IMMUNOFLUORESCENT EXAMINATIONS OF $60 \mu \mathrm{H}$. OF TREPONEMA PALLIDUM SUSPENSIONS HAVING ONE ORGANISM PER DARKFIELD (440 X) CENTRIFUGED FOR VARIOUS TIMES AT 13,160 RELATIVE CENTRIFUGAL FORCE

\begin{tabular}{|c|c|c|c|c|c|c|c|c|}
\hline \multirow{3}{*}{$\underset{(\min .)}{\text { Time }}$} & \multicolumn{4}{|c|}{ Organisms per High Dry Field } & \multicolumn{4}{|c|}{ Organisms Recovered $\dagger$} \\
\hline & \multicolumn{2}{|c|}{ Average ${ }^{\star}$} & \multicolumn{2}{|c|}{ Range } & \multicolumn{2}{|c|}{ Number } & \multicolumn{2}{|c|}{ Per cent. } \\
\hline & DF & FA & DF & FA & DF & FA & $\mathrm{DF}$ & FA \\
\hline $\begin{array}{r}3 \\
10 \\
30 \\
60 \\
120\end{array}$ & $\begin{array}{l}2.09 \\
2.28 \\
3.03 \\
3.05 \\
3.20\end{array}$ & $\begin{array}{l}3 \cdot 18 \\
3 \cdot 84 \\
5 \cdot 10 \\
5 \cdot 16 \\
5 \cdot 28\end{array}$ & $\begin{array}{l}1 \cdot 71-2 \cdot 44 \\
1.94-2.60 \\
2 \cdot 61-3.40 \\
2 \cdot 67-3 \cdot 41 \\
2.90-3.81\end{array}$ & $\begin{array}{l}2 \cdot 64-3 \cdot 78 \\
2.58-4.50 \\
3.96-6.06 \\
3.90-6.96 \\
4 \cdot 02-7 \cdot 02\end{array}$ & $\begin{array}{r}7,662 \\
8,358 \\
11,108 \\
11,181 \\
11,731\end{array}$ & $\begin{array}{l}1,892 \\
2,285 \\
3,035 \\
3,070 \\
3,142\end{array}$ & $\begin{array}{l}34 \cdot 9 \\
38 \cdot 1 \\
50 \cdot 6 \\
50 \cdot 9 \\
53 \cdot 4\end{array}$ & $\begin{array}{r}8.6 \\
10.4 \\
13.8 \\
14.0 \\
14.3\end{array}$ \\
\hline
\end{tabular}

Average values of 800 random fields derived from 100 fields of $10-\mu 1$. samples from the bottom portion of eight centrifuged microhaematocrit

iTotal recoverable organisms in $60 \mu \mathrm{l}$. calculated by the darkfield method to be 21,960 .

TABLE III

TREPONEME CONCENTRATIONS AT DIFFERENT TUBE LEVELS AND CRITOCAP SURFACE DETERMINED BY DARKFIELD AND DIRECT IMMUNOFLUORESCENT EXAMINATIONS OF $60 \mu \mathrm{I}$. OF TREPONEMA PALLIDUM SUSPENSIONS HAVING ONE ORGANISM PER DARKFIELD (440 X) CENTRIFUGED 30 MIN. AT 13,160 RELATIVE CENTRIFUGAL FORCE

\begin{tabular}{|c|c|c|c|c|c|c|c|c|}
\hline \multirow{3}{*}{ 10- $\mu 1$. Samples } & \multicolumn{4}{|c|}{ Organisms Per High Dry Field } & \multicolumn{4}{|c|}{ Organisms Recovered $\dagger$} \\
\hline & \multicolumn{2}{|c|}{ Average* } & \multicolumn{2}{|c|}{ Range } & \multicolumn{2}{|c|}{ Number } & \multicolumn{2}{|c|}{ Per cent. } \\
\hline & DF & FA & DF & FA & DF & FA & DF & FA \\
\hline \multirow{2}{*}{$\begin{array}{l}\text { Tube end opposite sediment } \\
\text { Sediment } \\
\text { Critocap surface } \\
\text { Combination of sediment and } \\
\text { critocap surface }\end{array}$} & $\begin{array}{l}0 \cdot 24 \\
3 \cdot 09 \\
1 \cdot 78\end{array}$ & $\begin{array}{l}0 \cdot 42 \\
5 \cdot 16 \\
2 \cdot 94\end{array}$ & $\begin{array}{l}0.07-0.41 \\
2 \cdot 81-3 \cdot 50 \\
1 \cdot 43-2 \cdot 21\end{array}$ & $\begin{array}{l}0 \cdot 18-0 \cdot 60 \\
4 \cdot 38-6 \cdot 12 \\
2 \cdot 64-3 \cdot 24\end{array}$ & $\begin{array}{r}880 \\
11,328 \\
6,525\end{array}$ & $\begin{array}{r}250 \\
3,070 \\
1,749\end{array}$ & $\begin{array}{r}4 \cdot 0 \\
51 \cdot 6 \\
29 \cdot 7\end{array}$ & $\begin{array}{r}1 \cdot 1 \\
14 \cdot 0 \\
8 \cdot 0\end{array}$ \\
\hline & $5 \cdot 39$ & $8 \cdot 46$ & $4 \cdot 49-5 \cdot 90$ & $7 \cdot 08-9 \cdot 48$ & 19,760 & 5,034 & 89.9 & 22.9 \\
\hline
\end{tabular}

^Average values of 800 random fields derived from 100 fields of $10-\mu l$. samples from the indicated sampling of eight centrifuged microhaematocrit tubes.

†Total recoverable organisms in $60 \mu \mathrm{l}$. calculated by the darkfield method to be 21,960 .

sites indicated in Table III showed variance significant beyond the 0.001 level for the FA and darkfield procedures.

\section{Discussion}

The relatively recent microscopical demonstrations of treponemes in the fluid of the anterior chamber of the eye and CSF of presumed adequately treated syphilitics have been made with the conventional darkfield technique or the direct FA method or both, with and without centrifugation. The reports have stimulated considerable interest and speculation about the concepts of adequate therapy in late syphilis, and about the immunological aspects of the disease. There has not, however, been complete acceptance that all of the demonstrated organisms were in fact $T$. pallidum.

Because these reports are not completely accepted and because of the important implications involved, it has become apparent that there is a strong need for the assessment of the reliability and relative efficiences of the darkfield and FA methods and the value of centrifugation for the demonstration of small numbers of treponemes in small volumes of fluid when sample sizes, such as aqueous humour aspirated from the anterior chamber of the eye, cannot be increased.

The search for treponemes in eye and CSF by the darkfield method is generally quite timeconsuming and can involve careful examination of hundreds, even thousands, of fields before even one organism is located. Because of the usually small number of organisms it appeared desirable to investigate the concentration and recovery of treponemes. The microhaematocrit tube and centrifuge seemed to be applicable, since the equipment is available in many laboratories and the Critocap provides adequate closure and easy access to the sedimented organisms.

There are certain differences between the darkfield and FA methods of identifying spiral-appearing organisms as $T$. pallidum. The conventional, and generally accepted, identification of $T$. pallidum requires the organism to have typical morphology and motility. $T$. pallidum organisms were identified 
on the basis of morphology alone in some of the reports, and this is one reason these have not been completely accepted. It is reasonable to doubt the identification of spiral-appearing organisms as $T$. pallidum, since certain artefacts may simulate the morphology of the treponeme. The FA method has not been used extensively for the identification of $T$. pallidum from clinical material, and there is possibly a lack of confidence in the method which may be associated with little or no personal experience. If one uses a conjugate that has been absorbed with Reiter organisms to remove common antibody (Deacon and Hunter, 1962; Meyer and Hunter, 1967), the conjugate becomes highly specific, in our opinion, for the identification of T. pallidum by the direct FA method. Also, in our opinion, when morphology is supported by immunofluorescence, the FA method is more reliable than darkfield identification based on spiral appearance without motility.

Preliminary centrifugation studies demonstrated the need for the maximum RCF attainable with the microhaematocrit centrifuge (Table I), and also that centrifugation for periods longer than 30 min. resulted only in minor increases in the number of organisms recovered (Table II). By darkfield enumeration, the organisms recovered in the sediment after centrifugation for $30 \mathrm{~min}$. at 13,160 RCF, shown in all three tables, was 50-55 per cent. of the calculated number in the $60-\mu l$. sample of the control treponeme suspension. However, a considerable number of organisms adhered to the Critocap surface, and when they were suspended in the $10 \mu \mathrm{l}$. containing the sediment the recovery increased to 89.9 per cent. (Table III).

The maximal recovery of organisms detected with the FA method was 22.9 per cent. (Table III), compared with 89.9 per cent. detected with the darkfield procedure. The lower percentage of detection with the FA method has been attributed to losses of organisms during the processing of the slides. Such losses would appear to demonstrate that the FA method is less efficient in comparison with the darkfield method. This was found not to be true when comparisons were made of the two methods in relation to the number of organisms found per hdf.

The data in all of the tables show that, although there were fewer organisms recovered with the FA method, the number of organisms found per field was greater with the FA method. This apparent paradox is clarified by a consideration of the differences of distribution of the organisms with each method. With the darkfield method the organisms were distributed over an area of 484 sq. mm.
$(22 \times 22-\mathrm{mm}$. coverslip) with a total of 3,666 fields, and with the FA method the same number was distributed over an area of 78.54 sq. $\mathrm{mm}$. (1-cm. circle) with a total of 595 fields. The difference in distribution area results in a six-fold concentration of the organisms, per unit area, with the FA method. Although there was a loss of $77 \cdot 1$ per cent. of organisms with the FA method in comparison with a loss of 10.1 per cent. with the darkfield method, the 22.9 per cent. that were recovered were concentrated in one-sixth the area of the darkfield method, and this accounts for the greater number of organisms per hdf found with the FA method. It is obvious that the FA method would have greater efficiency if losses of organisms during processing could be reduced, and this aspect of the method needs investigation.

\section{Summary}

A centrifugation technique for the concentration of Treponema pallidum with later identification by darkfield and immunofluorescent techniques was evaluated. The described technique enhances the demonstration of treponemes when small volumes of fluids are available which contain small numbers of treponemes, such as aqueous humour. Fluids were centrifuged in microhaematocrit tubes at 13,160 relative centrifugal force for $30 \mathrm{~min}$. in a microcapillary centrifuge. The maximal recovery of sedimented treponemes was accomplished by combining the organisms of the sediment with those adhering to the plastic cap.

Of the total number of organisms present in the control suspension, 89.9 per cent. were accounted for by darkfield examination after centrifugation, whereas $\mathbf{2 2 . 9}$ per cent. were demonstrated by direct FA staining. Although fewer organisms were demonstrated with the FA method, the number of organisms found per field was greater than the number per field with the darkfield procedure because with the FA method the organisms are concentrated six-fold.

The authors wish to express their appreciation to Mrs Eleanor V. Price and Mr Dennis D. Tolsma of the Venereal Disease Program for statistical assistance.

\section{REFERENCES}

Deacon, W. E., and Hunter, E. F. (1962). Proc. Soc. exp. Biol. (N.Y.), 110, 352.

Girard, K. F., Goldman, J. N., Baumstark, J. S., and STICKLE, D. W. (1967). "Observations on Late Congenital Syphilis with Ocular Disease: Laboratory Aspects". Presented at the 95th Annual Meeting of the American Public Health Association, Laboratory Section, Miami Beach, Florida, October 24, 1967. 
Goldman, J. N., and Girard, K. F. (1967). Arch. Ophthal. (Chicago), 78, 47.

,-- (1968). Ibid., 79, 716.

Meyer, P. E., and Hunter, E. F. (1967). F. Bact., 93, 784.

Morgan, H. J., and Vryonis, G. P. (1938). Amer. $\mathcal{F}$. Syph., 22, 462.

Smith, J. L., and Israel, C. W. (1967a). Arch. Ophthal. (Chicago), 77, 474.

— — (1967b). F. Amer. med. Ass., 199, 980.

USPHS (1964). "Serologic Tests for Syphilis-1964 Manual". US Communicable Disease Center, PHS Publication No. 411. U.S. Government Printing Office, Washington, D.C.

VDRL (1967). "A Provisional Technique for the Direct Immunofluorescent Identification of Treponema pallidum in Body Fluids and Tissue Sections in Current Use at the Venereal Disease Research Laboratory", June 15, 1967. Venereal Disease Research Laboratory, National Communicable Disease Center, Atlanta, Georgia 30333.

Wells, J. A., and Smith, J. L. (1967). Amer. F. Ophthal., 63, 410.

Wilkinson, A. E., and Jones, B. (November, 1967). Personal communication.

L'évaluation des techniques immunofluorescentes et sur fond noir pour la démonstration des
Treponema pallida dans les fluides contenant un petit nombre d'organismes

\section{RÉSUMÉ}

Une technique de centrifugation pour la concentration des Treponema pallida pour leur identification ultérieure par les techniques immunofluorescentes et sur fond noir a été évaluée. La technique décrite augmente la démonstration des tréponèmes quand de petits volumes de liquide sont disponibles et contiennent un petit nombre de tréponèmes, telle que l'humeur aqueuse. Les liquides sont centrifugées dans des tubes microhématocrites à une force centrifuge de 13,160 pendant trente minutes dans un centrifuge microcapillaire. La récuperation maxima des tréponèmes sédimentaires avait été accomplie en combinant les organismes du sédiment à ceux adhérant au bouchon plastique.

$\mathrm{Du}$ nombre total d'organismes présents dans la suspension "témoin", 89,9 pour cent avaient été expliqués par l'examen sur fond noir après centrifugation, tandis que 22,9 pour cent avaient été demontrés par la méthode colorante directe FA. Malgré que moins d'organismes avaient été démontrés par la méthode FA, le nombre d'organismes trouvés par champ était plus grand que le nombre vu par champ quand le procédé sur fond noir était employé parce que les organismes étaient concentrés six fois plus avec la méthode FA. 